\title{
PERBANDINGAN EFEKTIVITAS KOMBINASI CARVEDILOL - RAMIPRIL DAN BISOPROLOL - CANDESARTAN PADA PASIEN GAGAL JANTUNG KONGESTIF DI RSUD CIAWI
}

\author{
Ferry Effendi $^{*}$, Arief Muhamad 2 \\ 1. Program Studi Farmasi Sekolah Tinggi Teknologi Industri dan Farmasi Bogor \\ 2. Mahasiswa Program Studi S1 Farmasi Sekolah Tinggi Teknologi Industri dan Farmasi \\ Bogor \\ Korespondensi: ferry@sttif.ac.id
}

\begin{abstract}
ABSTRAK
Salah satu faktor penyebab gagal jantung yaitu hipertensi yang tidak terkontrol. Carvedilol Ramipril dan Bisoprolol - Candesartan dilaporkan efektif mengontrol tekanan darah. Penelitian ini bertujuan untuk membandingkan efektivitas 2 kombinasi obat tersebut. Data didapat dari rekam medis dan dianalisis dengan SPSS versi 25. Kelompok umur 46-55 tahun paling mendominasi sebanyak 75,86\%, jenis kelamin laki-laki mendominasi sebanyak 56,89\%. Kelas NYHA II paling mendominasi sebanyak 54,31\%. Perbandingan efektivitas kategori sistolik maupun diastolik tidak terdapat perbedaan yang bermakna dengan nilai $\mathrm{P}$ value sebesar 0,237>0,05 (sistolik), dan 0,075> 0,05 (diastolik). Dari hasil uji distribusi frekuensi, pencapaian target tekanan darah kombinasi Bisoprolol - Candesartan $(89,7 \%)$ lebih baik dibandingkan dengan kombinasi Carvedilol Ramipril (81\%).
\end{abstract}

\section{Kata Kunci : Bisoprolol, Candesartan, Carvedilol,Gagal Jantung, Ramipril}

\begin{abstract}
One of the contributing factors congestive heart failure is uncontrolled hypertension. Carvedilol Ramipril and Bisoprolol - Candesartan is reported to be effective in lowering blood pressure. This study aims to compare the effectiveness of the two drug combinations. Data collection from medical records. The data were tested and analyzed with the SPSS versi 25 . For 46-55 years age group, the most dominant was $75,86 \%$. From gender, it was more common in men total $56.89 \%$. class NYHA II is the most dominant class with total 54,31\%. For comparison of effectiveness the systolic or diastolic category, was no significant difference with $\mathrm{P}$ value was $0.237>0.05$ (systolic) and 0.075> 0.05 (diastolic). Result the distribution test, more patients who received Bisoprolol Candesartan therapy reached the target blood pressure $(89,7 \%)$ compared to with Carvedilol Ramipril (81\%).
\end{abstract}

\section{Keywords: Bisoprolol, Candesartan, Carvedilol, Heart Failure, Ramipril}

\section{PENDAHULUAN}

Gagal jantung merupakan masalah kesehatan masyarakat yang utama di seluruh dunia. Gagal jantung adalah syndrome klinis (sekumpulan tanda dan gejala), ditandai oleh sesak nafas (saat istirahat atau aktivitas) yang disebabkan oleh kelainan stuktur atau fungsi jantung [1]. Penyakit degeneratif tidak bisa dianggap sebelah mata, terbukti saat ini penyakit degeneratif menyebabkan kematian lebih besar. Penyakit degeneratif di Indonesia yang masuk lima besar penyebab kematian tersebut adalah gagal jantung [2].

Gagal jantung merupakan manifestasi klinis dari hipertensi yang tidak terkontrol, perlu penatalaksanaan yang tepat untuk menekan angka kematian akibat penyakit gagal jantung, dimulai dari pemberian monoterapi obat antihipertensi, apabila pemilihan monoterapi tidak berhasil harus segera dilakukan pemberian obat kombinasi antihipertensi [3]. Peresepan yang diterimapasien gagal jantung dimaksudkan untuk menjaga tekanan darah dalam batas normal yaitu 120/80 mmHG sehingga dapat mengurangi beban kerja jantung, apabila target tekanan darah tidak tercapai dengan monoterapi perlu segera diberikan terapi kombinasi [4].

Berdasarkan hasil penelitian sebelumnya, yang dilakukan di karanganyar pada tahun 2019 tentang pola penggunaan kombinasi dua obat 
antihipertensi, kombinasi dua obat antihipertensi terbanyak merupakan golongan Beta Blocker dan ARB dengan persentase $36,6 \%$, dan kombinasi kedua golongan obat tersebut paling tinggi efektivitasnya dibandingkan kombinasi golongan yang lain dengan persentase $86,7 \%$ kombinasi obat bisoprolol - candesartan pada terapi gagal jantung kongestif di RSUD Ciawi

\section{METODE PENELITIAN}

Jenis penelitian ini adalah penelitian observasional analitik dengan pengumpulan data secara retrospektif yang dilakukan dengan pengamatan melalui data sekunder rekam medik pasien gagal jantung kongestif. Sampel yang digunakan berjumlah 116 sampel setelah dihitung menggunakan rumus slovin.

Data yang diperoleh akan dianalisis dengan SPSS versi 25, dengan menggunakan uji Kolmogorov Smirnov untuk menganalisis apakah data terdistribusi normal atau tidak normal dan uji Independent Sample T-Test untuk mengetahui perbandingan efektivitas penggunaan kombinasi obat Carvedilol Ramipril, atau Bisoprolol - Candesartan, serta uji Distribusi Frekuensi untuk melihat gambaran sosiodemografi pasien dan menentukan persentase perbandingan efektivitas dari kombinasi kedua obat tersebut

\section{HASIL DAN PEMBAHASAN}

\section{Karakteristik Sosiodemografi Pasien Berdasarkan Umur}

Hasil penelitian yang dilakukan di ruang rawat inap RSUD Ciawi dari total 116 pasien yang dijadikan sampel, kelompok umur 17-25 tahun terdapat 1 pasien $(1,7 \%)$ yang mendapatkan terapi Carvedilol - Ramipril, sedangkan yang mendapatkan terapi Bisoprolol - Candesartan terdapat 2 pasien $(3,4 \%)$. Pada kelompok umur 26-35 tahun terdapat 3 pasien $(5,2 \%)$ yang mendapatkan terapi Carvedilol Ramipril dan 2 pasien $(3,4 \%)$ yang mendapatkan terapi Bisoprolol - Candesartan. Pada kelompok umur 36-45 tahun terdapat 11 pasien $(19,0 \%)$ dengan terapi Carvedilol Ramipril dan 9 pasien $(15,5 \%)$ dengan terapi Bisoprolol - Candesartan. Dan yang terakhir kelompok umur 46-55 tahun adalah yang paling mendominasi, dapat dilihat dari jumlah pasien yang mendapatkan terapi Carvedilol Ramipril terdapat 43 pasien $(74,1 \%)$, sedangkan yang mendapatkan terapi Bisoprolol Candesartan 45 pasien $(77,6 \%)$.
[5]. Tujuan Penelitian ini untuk mengetahui gambaran sosiodemografi pasien yang terkena gagal jantung kongestif di RSUD Ciawi dan untuk mengetahui perbandingan efektivitas antara kombinasi obat carvedilol - ramipril.

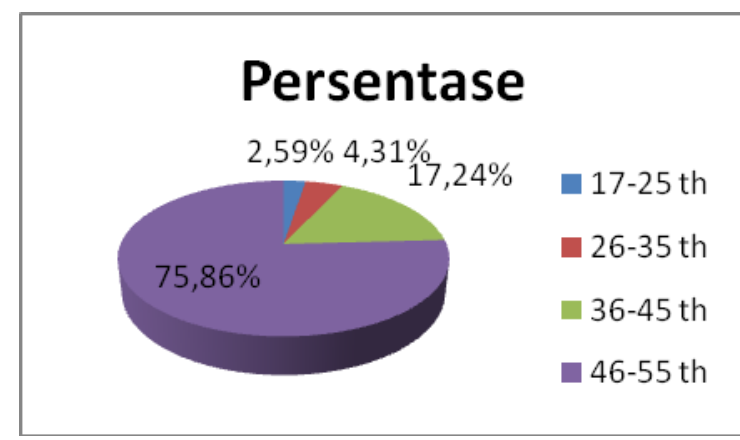

Gambar 1. Diagram Berdasarkan Umur

Data yang diteliti di ruang rawat inap RSUD Ciawi sejalan dengan teori, hal ini merupakan hal yang wajar dikarenakan semakin meningkatnya umur seseorang maka fungsi organ-organ tubuhnya pun semakin menurun. Hal ini didukung oleh penelitian Yayang, dkk. (2016) di Yogyakarta bahwa kelompok umur terbanyak responden gagal jantung yang diteliti ialah kelompok usia 50-65 tahun dimana umur tersebut merupakan 59\% dari jumlah responden keseluruhan [6].

\section{Karakteristik Sosiodemografi Pasien Berdasarkan Jenis Kelamin}

Penelitian yang dilakukan oleh Sani (2017) di Jakarta memberikan gambaran yang jelas tentang penyakit gagal jantung kongestif. Pada studinya disebutkan bahwa kejadian gagal jantung per tahun pada orang berusia > 45 tahun adalah 7,2 kasus setiap 1000 orang lakilaki dan 4,7 kasus setiap 1000 orang perempuan, yang berarti jumlah pasien gagal jantung laki-laki lebih banyak dari pasien gagal jantung perempuan [7].

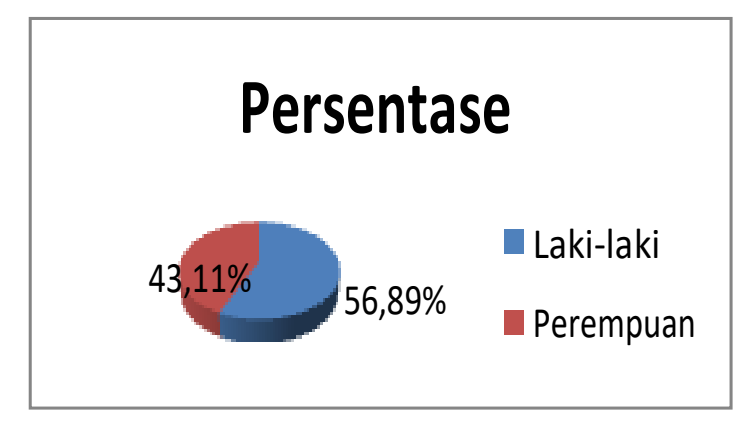

Gambar 2. Diagram Berdasarkan Jenis Kelamin 
Data yang diteliti di ruang rawat inap RSUD Ciawi sejalan dengan penelitian yang dilakukan oleh Sani (2017) yang menyatakan bahwa kasus gagal jantung kongestif yang terjadi di RSUD Ciawi lebih banyak terjadi pada laki-laki $(56,89 \%)$ dibandingkan dengan perempuan $(43,11 \%)$. Hal ini dikarenakan lakilaki memiliki aktivitas fisik yang lebih berat dibandingkan dengan perempuan, sehingga membuat jantung terbiasa bekerja lebih berat. Selain itu gaya hidup laki-laki cenderung lebih tidak sehat dibandingkan dengan perempuan seperti kebiasaan merokok, mengonsumsi alkohol, dan kurang tidur, hal itu merupakan faktor pencetus terjadinya penyakit hipertensi yang jika diabaikan akan berdampak serius pada kesehatan jantung.

\section{Karakteristik Sosiodemografi Pasien Berdasarkan Kelas Gagal Jantung}

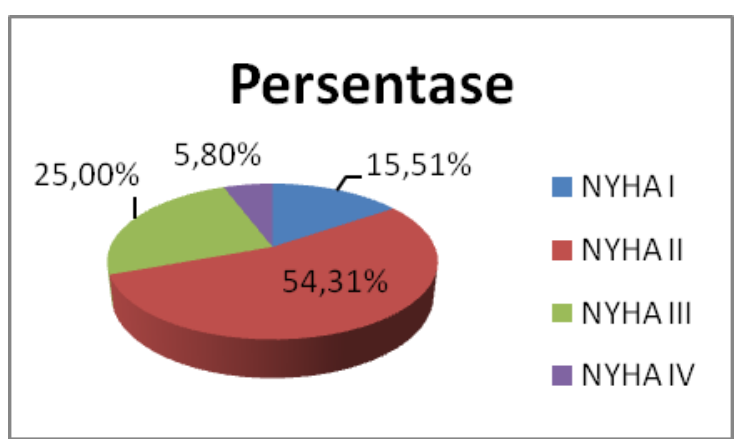

Gambar 3. Diagram Berdasarkan Kelas Gagal Jantung

Hasil penelitian yang dilakukan di ruang rawat inap RSUD Ciawi dari total 116 pasien yang dijadikan sampel, terdapat 16 pasien $(27,6 \%)$ mendapatkan terapi Carvedilol Ramipril dan 2 pasien $(3,4 \%)$ mendapatkan terapi Bisoprolol - Candesartan untuk kelas NYHA I. Kemudian kelas NYHA II adalah kelas NYHA yang paling mendominasi dari penelitian ini dengan 28 pasien $(48,3 \%)$ mendapatkan terapi Carvedilol - Ramipril dan 35 pasien $(60,3 \%)$ mendapatkan terapi Bisoprolol - Candesartan. Untuk kelas NYHA III terdapat 12 pasien (20,7\%) yang mendapatkan terapi Carvedilol - Ramipril dan 17 pasien $(29,3 \%)$ yang mendapatkan terapi Bisoprolol - Candesartan. Dan kelas yang terakhir yaitu NYHA kelas IV merupakan kelompok kelas yang paling rendah dengan jumlah 2 pasien $(3,4 \%)$ mendapatkan terapi Carvedilol - Ramipril dan 4 pasien $(6,9 \%)$ mendapatkan terapi Bisoprolol - Candesartan.
Hasil penelitian ini sejalan dengan hasil penelitian yang dilakukan oleh Sari, dkk. (2017) di Manado, yang menyebutkan bahwa distribusi pasien gagal jantung kongestif menurut kelas NYHA terbanyak berada pada NYHA II, sedangkan yang paling rendah berada pada NYHA IV. Status fungsional penderita gagal jantung kongestif telah dibakukan berdasarkan klasifikasi NYHA (New York Heart Asociation) kelas I-IV [8].

\section{Perbandingan Efektivitas Kategori Sistolik}

Tabel 1. Output Indenpent T-Test Kategori Sistolik

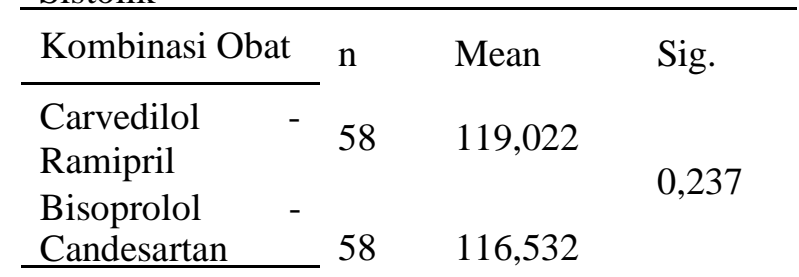

Hasil mean (rata-rata) dari kedua kelompok kombinasi obat yaitu 119,022 untuk kombinasi Carvedilol - Ramipril dan 116,532 untuk kombinasi Bisoprolol - Candesartan dengan nilai $\mathrm{P}$ value $0,237>0,05$ yang berarti tidak terdapat perbedaan yang bermakna antara efektivitas kombinasi Carvedilol - Ramipril dan Bisoprolol - Candesartan untuk kategori sistolik pada terapi gagal jantung kongestif di RSUD Ciawi.

Hal ini juga sejalan dengan penelitian yang dilakukan oleh Yanti, dkk. di Medan pada Juni 2020 tentang perbandingan efektivitas penurunan tekanan darah kombinasi obat golongan Angiotensin Reseptor Blocker - Beta Blocker dan Angiotensin Converting Enzym inhibitor - Beta Blocker. Hasil penelitiannya menunjukan bahwa tidak terdapat perbedaan efektivitas antara 2 kombinasi golongan obat tersebut.

\section{Perbandingan Efektivitas Kategori Diastolik}

Tabel 2. Output Independent T-Test Kategori Diastolik

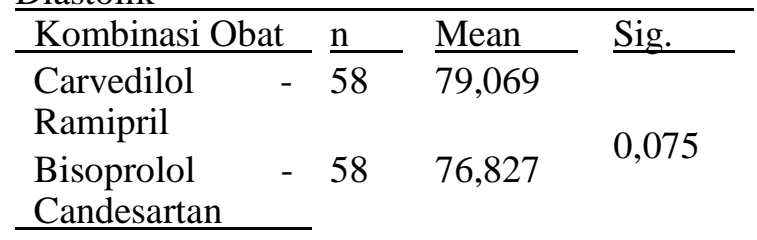


Hasil mean (rata-rata) dari kedua kelompok kombinasi obat yaitu 79,069 untuk kombinasi Carvedilol - Ramipril dan 76,827 untuk kombinasi Bisoprolol - Candesartan dengan nilai $\mathrm{P}$ value $0,075>0,05$ yang berarti tidak terdapat perbedaan yang bermakna antara efektivitas kombinasi Carvedilol - Ramipril dan Bisoprolol - Candesartan untuk kategori diastolik pada terapi gagal jantung kongestif di RSUD Ciawi.

Hasil penelitian ini juga sejalan dengan penelitian yang dilakukan oleh Wati (2019) di Padang tentang Perbandingan Efek Penurunan Tekanan Darah Penggunaan Kombinasi 2 obat Antihipertensi Candesartan - Amlodipin dan Candesartan - Furosemid. Dari hasil penelitian yang disajikan dapat disimpulkan bahwa keduanya sama-sama memberikan efek penurunan tekanan darah sistolik maupun diastolik pada pasien, dan tidak ditemukan perbedaan yang bermakna dengan nilai $\mathrm{P}$ value $>0,05$.

\section{Uji Distribusi Frekuensi Tingkat Pencapaian} Tekanan Darah

Tabel 3. Pencapaian Target Tekanan Darah

\begin{tabular}{lll}
\hline $\begin{array}{l}\text { Kombinasi } \\
\text { Obat }\end{array}$ & Tercapai (\%) & $\begin{array}{l}\text { Tidak } \\
\text { Tercapai (\%) }\end{array}$ \\
\cline { 1 - 1 } $\begin{array}{l}\text { Carvedilol } \\
\text { Ramipril }\end{array}$ & $89,70 \%$ & $81 \%$ \\
$\begin{array}{l}\text { Bisoprolol } \\
\text { Candesartan }\end{array}$ & $11,30 \%$ & $19 \%$ \\
\hline
\end{tabular}

Berdasarkan hasil uji statistik menggunakan Independent T-Test didapatkan hasil bahwa tidak terdapat perbedaan efektivitas yang bermakna baik kategori sistolik maupun diastolik antara kombinasi Carvedilol Ramipril dan Bisoprolol - Candesartan, namun jika dilihat lebih rinci menggunakan uji distribusi frekuensi, pasien yang mendapatkan terapi kombinasi Bisoprolol - Candesartan lebih banyak yang mencapai target tekanan darah sebanyak 52 pasien $(89,7 \%)$ dibandingkan dengan kombinasi Carvedilol Ramipril sebanyak 47 pasien (81\%).

Hasil penelitian ini sejalan dengan teori yang di tulis oleh Rampengan (2014) dalam bukunya yang berjudul Peran Terkini Beta Blocker Pada Pengobatan Kardiovaskular. Di dalam buku tersebut dituliskan bahwa Bisoprolol merupakan salah satu Beta Blocker selektif kardiovaskular, yang berarti bahwa
Bisoprolol hanya menghambat reseptor $\beta-1$ adrenergik di jantung sehingga penggunaan Bisoprolol akan mendapatkan efek yang maksimal pada pengobatan gagal jantung, berbeda dengan Carvedilol yang merupakan Beta Blocker non selektif.

\section{SIMPULAN}

Pasien yang mendapatkan terapi kombinasi Bisoprolol - Candesartan lebih banyak yang mencapai target tekanan darah sebanyak 52 pasien $(89,7 \%)$ dibandingkan dengan kombinasi Carvedilol - Ramipril sebanyak 47 pasien (81\%). Sehingga dapat disimpulkan kombinasi Bisoprolol - Candesartan lebih efektif dibandingkan dengan kombinasi Carvedilol Ramipril.

\section{DAFTAR PUSTAKA}

[1] Wulandari, T. 2018. Gambaran Penggunaan Obat Pada Pasien Gagal Jantung Kongestif Rawat Inap. Jurnal UNTAN. Vol. 3 (1). Pontianak

[2] Widowati U. 2015. 10 Penyakit Paling Mematikan di Indonesia. CNN Indonesia 14/05/2015. Diakses dari http/www.CNNIndonesia.com pada tanggal [10 Januari 2021 jam 20.25 WIB]

[3] Johnson RJ, Fehally J, Floege J. 2015. Comprehensive Clinical Nephrology, 5th edition. Elseiver Saunders. Philadelpia

[4] PERKI. 2015. Pedoman Tata Laksana Gagal Jantung. edisi pertama.

[5] Tri, W. 2019. Pola Penggunaan Kombinasi Dua Obat Antihipertensi Pada Pasien Hipertensi. Jurnal Ilkes (Ilmu Kesehatan). Vol. $10: 77-82$

[6] Yayang, dkk. 2016. Gambaran Karakteristik Pasien Gagal Jantung Usia 45-65 Tahun di Rumah Sakit PKU Muhammadiyah Gamping Sleman. Indonesian Journal Nursing Practices. Vol. 1 (1). Hal 55-59. Yogyakarta

[7] Sani, L. 2017. Gambaran Sosiodemografi Pasien Gagal Jantung Kongestif di Provinsi DKI Jakarta. Jakarta

[8] Sari, Patricia Ratna, dkk. 2017. Hubungan Kelas NYHA Dengan Fraksi Ejeksi Pada Pasien Gagal Jantung Kongestif. Jurnal Pendidikan Keperawatan Indonesia. Vol. 2 : 140-151. Manado

[9] Yanti, dkk. 2020. Perbandingan Efektivitas Penurunan Tekanan Darah Kombinasi Obat Golongan Angiotensin Reseptor Blocker - Beta Blocker dan 
28| Ferry Effendi et al.,( Perbandingan Efektivitas Kombinasi Carvedilol....)

[10] Angiotensin Converting Enzym inhibitor Beta Blocker. Jurnal Riset BB Medan. Vol. 5 No. $1: 31-38$

[11] Wati, M. 2019. Perbandingan Efek Penurunan Tekanan Darah Penggunaan Kombinasi 2 obat Antihipertensi
Candesartan - Amlodipin dan Candesartan - Furosemid. Padang

[12] Rampengan, Starry Homenta. 2014. Peran Terkini Beta-Blocker Pada Pengobatan Kardiovaskular. edisi pertama : Badan Penerbit FKUI. Jakarta. Hal 235-23 